\title{
Multidimensional Approach to Suicide Prevention in Jails and Prisons: The Best Defense against Liability Lawsuits
}

\author{
Anasseril E. Daniel \\ Correctional psychiatry, Daniel Forensic Psychiatric Services, Columbia, Missouri \\ Email: aedaniel@aol.com
}

How to cite this paper: Daniel, A.E. (2021) Multidimensional Approach to Suicide Prevention in Jails and Prisons: The Best Defense against Liability Lawsuits. Open Journal of Psychiatry, 11, 248-264. https://doi.org/10.4236/ojpsych.2021.11402 $\underline{0}$

Received: August 26, 2021

Accepted: September 15, 2021

Published: September 18, 2021

Copyright $\odot 2021$ by author(s) and Scientific Research Publishing Inc. This work is licensed under the Creative Commons Attribution International License (CC BY 4.0).

http://creativecommons.org/licenses/by/4.0/

\begin{abstract}
Inmates in jails and prisons are a high-risk group for suicide. Often, legal claims of medical negligence and $\$ 1983$ based on deliberate indifference by the correctional officials follow. Unique stable and dynamic factors and circumstances and their interaction explain most suicides. A systematic suicide screening using a well-designed suicide screening questionnaire that captures known risk factors will identify most inmates at risk if adequately used. Identification and subsequent mental health assessment set the stage for preventive intervention, monitoring, and treatment of the inmates. A multidimensional suicide prevention program saves not only lives but also the best defense against a liability lawsuit.
\end{abstract}

\section{Keywords}

Suicide in Jails and Prisons, Preventing Suicide in Jails, Correctional Lawsuits, Deliberate Indifference Claims, Medical Malpractice, Theories of Suicide in Jails

\section{Introduction}

Suicide in jails and prisons is a significant public health issue in the United States and worldwide. It is the leading cause of death in jails [1] and the third in prisons. Lawsuits follow a substantial number of suicides.

Two types of claims are usually made: 1) malpractice, mostly against health-care providers, often litigated in state courts; and 2) $\$ 1983$ civil rights violation claims litigated in federal courts. Sometimes, both types of claims may be made simultaneously.

The elements required to support a medical negligence claim include the fol- 
lowing: 1) duty of care owed to the inmate, 2) breach of such duty, 3) proximate relationship between the breach of duty and the injury, and 4) claim of damages. The issue is whether a health-care provider deviated from the standard of care and whether such negligence had any nexus to the injury or death of the inmate. A claim of wrongful death is the same as a malpractice claim.

The typical allegation in a deliberate indifference complaint focuses on how the facility officials and health-care providers intentionally disregarded an inmate's serious medical need, violating his constitutional right, embedded in the Eighth Amendment protection against cruel and unusual punishment. Often, the $\$ 1983$-based lawsuit includes claims of poor staffing and lack of staff training causing and contributing to inmate suicide. Such claims have their origin in Monnell v. Department of Social Services, New York City [2].

There is no general agreement on what constitutes deliberate indifference and the standard of proof required to prevail in such a claim. Landmark court decisions established that the prisoners have a constitutional right to receive health care meeting minimum standards [3] [4]. In Bowring v. Godwin (1977) [4], the court emphasized the lack of underlying distinction between the right to medical care for physical illness and its psychological or psychiatric counterpart. An inmate's substantial probability of engaging in serious self-harm or suicide would constitute a serious medical need requiring active intervention. Deliberate indifference occurs when an official disregards the risk of such serious harm.

In Farmer v. Brennan (1976) [5], in one of the earliest cases, Justice Souter positioned the required standard of proof between negligence on the one hand and acting with purpose or intent on the other, which amounts to "recklessness". The plaintiff is required to show that the defendants (prison officials or health-care professionals) "knew" (had actual knowledge as opposed to should have known) the serious medical need and disregarded the "excessive risk to inmate's health or safety".

Later, various federal courts delineated the elements for a plaintiff to be successful on a $\$ 1983$ claim. The court in the Palakovic [6] case established that 1 ) the individual should have a particular vulnerability to suicide, meaning that there was a "strong likelihood, rather than a mere possibility", that suicide would be attempted, 2) the prison official knew or should have known of the individual's particular vulnerability, and 3 ) the official acted with reckless or deliberate indifference, meaning something beyond mere negligence, to the individual's particular vulnerability. As opposed to the Brennan case, the court expanded the required element to include the "prison officials should have known" the vulnerability.

In Kempf $v$. Northumberland City Jail [7], the court determined the following: The (decedent) posed a significant suicide risk at the time he was booked and remained so throughout the confinement at (prison); and the placement of the (decedent) in a cell with known anchor points with bedsheets and clothing, knowing his obvious and substantial risk, amounted to deliberate indifference.

The presence of obvious and substantial risk factors often determines an in- 
mate's suicide vulnerability. Typically, the risk factors include active suicidal ideation with intent and plan; the presence of diagnosed mental disorder, particularly depression, anxiety, and agitation with hopelessness; a history of nearly lethal suicide attempts within the preceding six months to a year of the final act; and alcohol or opiate intoxication and withdrawal. In denying a summary judgment motion by the defendant in Lewis v. Northumberland County [8], the court indicated that the defendant had actual knowledge of Mr. Lewis's suicide vulnerability because of his most recent serious suicide attempt, opiate withdrawal, discontinuation of suicide watch prematurely, mental status changes, and his classification as a high risk for suicide. Based on these cases, the elements required to support a deliberate indifference claim include that the prison officials had actual knowledge of, or they should have known of, the inmate's suicide vulnerability.

\section{Inmates: A High-Risk Group for Suicide}

World Health Organization (WHO) statistics show that approximately 800,000 people (public) die by suicide worldwide every year. In the United States, 42,773 people took their lives in 2014, compared to 29,199 in 1999 [9]. In 2020, 45,173 died by suicide, making it the tenth leading cause of death by people of all ages. It is the second leading cause of death among people between the age of 15 and 29. White men over 55 years of age are at the highest risk of suicide. Annually, 12 per 100,000 in the community die by suicide.

For several decades before 2000, the suicide rate in US state prisons ranged from 18 to 40 , jails 52 to 129 , and federal prisons 10 to 17 per 100,000 [10] [11]. This rate has declined since 2001. The latest available statistics in 2016 show the rate in jails declined to 46 per 100,000 [11]. Suicide makes up 31\% of all deaths in jails. In 2016, like in prior years, $80 \%$ of the jails reported no suicide, while $13 \%$ reported one, and $7 \%$ reported two or more [11]. Although there was a decrease in the number of suicides, it was the leading cause of death in jails in 2016, with heart disease as the second [11]. The primary reason for the decline in the rate of suicide is better identification and monitoring of at-risk inmates and treatment intervention. In addition, there is an overall awareness that most suicides are preventable.

In state and federal prisons combined, the total number of deaths by any cause in 2016 was 4117 [12]. The number of deaths in state prisons rose 1.3\% from 2015 to 2016 (from 3682 to 3729), while the number of deaths in federal prisons fell 15\% (from 455 to 388). Each year from 2001 to 2016, an average of $88 \%$ of deaths in state prisons were due to natural causes, ranging from $89 \%$ in 2001 to $86 \%$ in 2016 . Over the same period, an average of $11 \%$ of deaths in state prisons was due to unnatural causes (suicide, drug, or alcohol intoxication). Further research shows the state prisons had 3300 deaths by suicide from 2001 to 2016, while federal prisons only had 260 .

As of 2016, the suicide rate in corrections has stabilized due to improved screening, identification, monitoring, and treatment of inmates at risk. However, 
the rate remains high, with 46 per 100,000 in jails and 17 per 100,000 in state prisons. Except for the federal prisons, which have a rate of 10 per 100,000, the rates remain high compared to the public, making the incarcerated population a high-risk group for suicide. The Bureau of Justice recognizes that underreporting-including not counting deaths occurring in the hospital after transfer following a suicide attempt and deaths occurring while on bond-remains a problem.

In the community, the high-risk groups for suicide include persons with psychiatric disorders, substance-abuse issues, newly diagnosed serious physical illnesses, and previous suicide attempts. Research shows that detainees and prisoners represent a high-risk group [13]. Risk factors in jails and prisons differ from the community in unique ways. The principal predictors of inmate suicide include gender of male, age over 55, previous near-lethal suicide attempts, alcohol and opioid withdrawal, intractable pain, depressive disorders with hopelessness, plans of suicide attempts, high suicide intent, and ongoing psychiatric treatment. However, clinical experience, case reports, and retrospective studies [14] show an exhaustive list of risk factors affecting inmates.

\section{Common Problems Identified in Liability Lawsuits}

\subsection{Misidentification of At-Risk Inmates}

Misidentification of the potential at-risk population at every point during incarceration from arrest through release is a significant issue. Most clinicians and officers are naturally perceptive and empathetic and can use their "sixth sense" in spotting a suicidal inmate. A correctional officer who believes that all inmates, regardless of mental illness, are manipulative, attention-seeking, and antisocial may miss an opportunity to intervene in crises and prevent an inmate from committing suicide [15].

\subsection{Lack of Standard Screening Questionnaire}

Lack of a standardized suicide screening instrument may result in inadequate risk assessment. Failure to explore key items in a screening questionnaire regarding current suicidal ideation, past suicide attempts, medication history, and the last use of drugs, particularly opiates, may negatively impact the detainees' care. More importantly, inadequate screenings may result in not placing a genuinely suicidal detainee/inmate on suicide watch.

\subsection{Inadequate Mental Health Assessment and Treatment Planning}

A major finding in the history of many inmates who commit suicide is the lack of or inadequate mental health assessment and treatment planning. Although many facilities mandate the development of treatment plans, a lack of consistent implementation of a treatment planning directive delays appropriate care.

\subsection{Inadequate and/or Lack of Periodic Suicide Risk Assessment}

Often suicide risk assessment in jails and prisons consists of limited queries of 
whether an inmate is having suicidal thoughts and plans instead of detailed examination of all risk factors in the context of protective factors to arrive at a reasoned conclusion that an inmate may or may not present a suicide risk.

\subsection{Discontinuation of Psychotropic Medication at the Entry to Jail or Prison}

Many inmates enter a jail or prison on prescription medications that include psychotropic agents and life-sustaining medications such as antihypertensives, antidiabetics, angina medications, and breathalyzers. On occasion, psychotropics are discontinued abruptly, causing severe withdrawal symptoms, increasing anxiety and agitation, predisposing the inmate to suicidal behaviors. Abrupt discontinuation of medication was cited in a successful deliberate indifference lawsuit [16].

\subsection{Failure to Obtain Medical and Psychiatric Records from Community Sources}

The failure to obtain records from community sources may cause a delay in care and adversely affect the determination of supervision and watch requirements and proper treatment planning.

\subsection{Failure to Provide "Bridge Medications"}

Understandably, it takes time to obtain an inmate's past psychiatric records or verify medications. However, based on the history provided by the inmate and clinical information obtained by a nurse or screener, it is appropriate to prescribe psychotropic medications to "bridge" the period until the required information becomes available. Failure to provide bridge medications may delay inmate health care, and sometimes, it leads to the precipitation of withdrawal symptoms or recurrence of psychiatric symptoms, including suicidal thoughts.

\subsection{Delay in Psychiatric Care}

Delayed psychiatric care can be portrayed as an intentional disregard of the serious medical need of an inmate. Various correctional standards emphasize the importance of critical timeframes in screening, referral, and evaluation. Intake is conducted on the day of arrival of the detainee to a jail or prison. Suicide screening is done in the first 24 hours. A mental health evaluation is completed within 24 hours of referral from the screener, while a psychiatric evaluation is done within 14 days except on emergency referrals. Medical services requests (MSRs) are responded to within 3 business days except in emergencies. Follow-up psychiatric contact is generally completed within 30 days. Delays in these timeframes may lead to poor care and potential suicidal behaviors.

\subsection{Failure to Implement Detoxification Protocol}

Often arrestees enter a jail intoxicated with alcohol or under the influence of opiates, including heroin and methamphetamine or a combination of substances. 
Recognition of the state of intoxication and initiating detoxification protocol will prevent distressing withdrawal symptoms, predisposing an inmate to suicidal ideation and behaviors.

\subsection{Falsification of Suicide Watch Logs}

A common problem is the falsification of suicide watch logs. Logs must be completed every 15 minutes or less at staggered intervals. It is not uncommon to find a straight line through the suicide watch log, clearly indicating a lack of accuracy of the suicide watch. The defense loses many lawsuits due to falsified documentation of suicide watch logs.

\subsection{Failure of Communication}

Failure of communication is a key issue in suicide prevention. This may occur at many levels: between the arresting officer and the booking officer, the booking officer and the mental health screener, the nursing staff and the psychiatrist, and the scheduler of appointments and the psychiatrist. Failure to schedule a potentially suicidal inmate with the psychiatrist may delay a critical psychiatric evaluation, risk assessment, and intervention.

A booking officer may have a prima facie or visceral impression that an arrestee is suicidal. Unless the officer communicates his impression to the booking officer, this valuable piece of information is missed. Some suicide screening questionnaires include a question to summarize the arresting officer's impression.

Nowadays, the screening questionnaire is computerized. If a suicide alert is posted on the computer by a screener, if there is no mechanism in the computer to display the alert, the mental health professional at the time of evaluation would be unaware of the alerts. Rarely, miscommunication may occur in the transfer of medication orders to the MAR.

Occasionally, a spouse or significant other may call a jail or prison to communicate a concern about the next of kin's potential suicide risk. Such calls are to be documented and the information given to the mental health providers for further action. If the jails or prisons do not have a system of documenting such calls, information crucial for suicide prevention may be lost.

Daniel and Fleming reported that $60 \%$ of inmates communicated their intent to outside people, but those who received the information often failed to communicate to the jail because they did not take it seriously, creating another type of communication problem [17].

Compartmentalization of documentation by the medical and mental health staff and the custody staff is the norm in jails and prisons, which restricts sharing critical information between the officers and mental health providers. HIPAA regulations may preclude the sharing of protected information.

A different level of communication problem may occur between an inmate and the officers. Some inmates in distress may try to reach an officer via intercom in their cell. Failure to respond to the intercom contact may be viewed by 
the inmate that "nobody cares". The author is aware of a situation in which an inmate tried to reach the control room via the intercom, which was ignored. In another situation, the intercom call display in the control room was muted. In both these situations, the inmates killed themselves a few minutes after their attempts at contact with the officers were thwarted.

Systematic communication among stakeholders can save lives. Reasonable communication between mental health and correctional staff is desirable. The intercom system must be functional.

\subsection{Classification Issues}

While inmates with mental illness may be considered to have special needs, mental illness is not a major consideration in custody risk assignment.

Classification of inmates, assignment of institutions (prisons), cell selection, cell movement, and placement in disciplinary segregation is entirely assigned to the correctional staff. The mental health staff usually provides input to the classification staff in assigning mentally ill inmates. From a suicide-prevention standpoint, such arrangements cause significant challenges, particularly when interdisciplinary communication is lacking. Failure to accept or provide mental health input may impact the cell assignment of a potential suicide inmate. Correctional officers primarily conduct inmate classification and cell assignment.

\subsection{Lack of Implementation of Policy and Procedures}

Besides the training, lack of implementation of the facilities policies and procedures, particularly those related to suicide prevention, is the most significant issue in suicide prevention.

\subsection{Training}

Proper training of correctional officers and mental health staff in identifying the inmate at risk is the single most significant factor in preventing suicide.

In almost every lawsuit involving suicide, the lack of training of officers and mental health staff will be cited to support a deliberate indifference or medical negligence claim. The claims may link the staff's lack of, or poor, training on risk factors and lack of knowledge of suicide-prevention policies and procedures, and failure to implement them directly to the inmate's suicide. Such an argument may be strong in cases where a cluster of suicides occurs during a period in the same jail where the claimant died. Sometimes, the lawsuit may claim the suicide rate in a particular jail or prison exceeds those of similar institutions during the same period. A cluster of suicides may reflect a lack of training of the staff.

\section{Understanding Inmate Suicide}

Inmates commit suicide due to a complex interaction of psychiatric, biological, genetic, and psychosocial factors, including institutional stress. Inmates housed in a controlled setting form an artificial but loosely integrated society. They 
come from different backgrounds, face either pretrial detention or serve variable sentences, and have different levels of coping skills and resources. In addition, they must comply with institutional restrictions, supervision, and rules, which some find unacceptable and intimidating and even rebel against, adding undue stress. Those who are placed in administrative segregation and maximum-security prisons face a very rigid environment and sensory deprivation. Essentially, the setting makes a difference in the life and psychological status of the inmates.

Theories of suicide include Durkheim's social integration, Shneidman's "psychache", Freud's death instinct, Joiner's interpersonal-psychological theory, and some lesser-known constructs such as Steve Taylor's social-psychological framework. Seligman's theory of learned helplessness and Beck's theory of hopelessness may explain the inmate's mental state at the time of suicide but do not fully explain why an inmate commits suicide.

Emile Durkheim, a French sociologist, put forth the most widely accepted theory of suicide in general. His theory is based on a person's integration into society. An integrated society is created when people's beliefs, values, and shared customs and traditions bind them together. According to him, suicide is inversely related to how best a person is integrated into society.

Durkheim classified suicide into egoistic, anomic, fatalistic, and altruistic types. The egoistic type best fits most of the suicides in jails and prisons because many inmates are disenfranchised and alienated from society, and they have an only limited anchors in their lives, unable to adjust to family and society. Anomic suicide involves those individuals whose situations have changed so dramatically that norms are not personally relevant. This type of suicide occurs among those whose status has changed drastically after the arrest, especially those who held high social status before their arrests. Fatalistic suicide occurs among inmates in maximum-security units and in administrative segregation, where they find themselves trapped with a feeling of "no way out", such as a life sentence without the possibility of parole. Altruistic suicide hardly ever occurs in a controlled setting such as a jail or prison.

Thomas Joiner [18] proposed that thwarted belongingness and being a burden on others is the basis of self-harm. His theory states that thwarted belongingness is a painful mental state in which a person's fundamental need for connectedness is unmet, and then the person feels like an undue burden to others. Such a mental state may be a significant factor in many inmates. A few serious, almost lethal, attempts and completed suicides occur immediately after divorce papers are filed or a rejection letter from a loved one is received.

Freud's theory is based on "Thanatos", the death instinct. Some inmates may entertain a death wish, which may or may not be obvious to others. Typically, middle-aged, chronically depressed inmates detained for minor offenses express their wish to die and act out impulsively. They are unlikely to have a history of prior suicide attempts or active suicidal ideation.

A more understood theory from a pragmatic perspective is that of Erik Erik- 
son, who postulated that a person commits suicide when overwhelming feelings of guilt exceed the ability to cope. Many first-time detainees fall into this category because of overwhelming guilt for their impulsive criminal behavior and lack of coping skills to adjust to a life behind bars. A female homicidal offender, particularly a battered spouse or partner who acted in self-defense to persistent abuse by her husband or partner, may find herself engaging in suicidal behaviors out of guilt because of her actions and lack of emotional coping resources.

Abramson et al. [19] initially proposed that hopelessness accounted for suicidal ideation and behavior. They further noted that suicidality is the core symptom of hopelessness and depression. Beck elaborated on the association between depression, hopelessness, and suicidality. Beck found that hopelessness is the predominant mental state in those who commit suicide almost $90 \%$ of the time.

Bonner and Rich [20] studied a stress-psychosocial vulnerability model of suicidal ideation and behavior in a jail population. They administered psychological measures of social alienation, cognitive distortions, adaptive resources, situational (jail environment) stress, depression, hopelessness, and suicidal ideation to 146 male inmates at a county jail facility. They found that a combination of low reasons for living, irrational beliefs, jail stress, and loneliness best explained suicide intent.

Thus, various theories and postulates suggest that depression, hopelessness, feeling trapped (helplessness), lack of connectedness, and guilt are the predominant mental states at the time of the suicidal act. Yet not all inmates who experience such states take their lives. The most plausible and easily understood explanation of custodial suicide incorporates the key elements of Durkheim's social integration model and Beck's theory of depression and hopelessness.

There is an association between the critical mental state and some behavior traits such as impulsivity, agitation, and tension among those who attempt or commit suicide. Impulsivity and aggression are highly correlated with suicidal behavior across psychiatric samples and nonpsychiatric populations. Impulsivity and aggression are related, but the nature of this relationship remains unclear, though many inmates are both impulsive and aggressive [21].

While correlation is not necessarily causation, it is worth examining the correlates of suicide. They are divided into static and dynamic factors. The static factors, as the name suggests, are non-variable factors. They include an age of over 55 , male sex, whites, severe mental disorder, substance abuse, maximum-security detention, pretrial status, past suicide attempt, and similar non-changeable factors. However, these are high-risk factors; not all inmates who have all or some of them kill themselves.

The commonly observed dynamic factors include loss of a loved one, impending divorce (which may be related to the arrest and potential criminal prosecution), loss of custody of children, an unusually long sentence, an unexpected additional charge or sentence, placement in a maximum-security unit, loss of dignity and standing in the community, and other similar psychosocial 
stressors. Other dynamic factors include (not in any particular order): alcohol intoxication and withdrawal, opioid/heroin withdrawal, and benzodiazepine withdrawal, mainly when there is minimal recognition of withdrawal symptoms or inadequate treatment.

When static factors individually or collectively interact with dynamic factors in an inmate's life, given the opportunity and the means, he or she takes his or her life. The dynamic factors, events, or circumstances act as immediate precipitants of the self-destructive act. Almost always, an event or circumstance occurs in an inmate's life that acts as a catalyst. Most of the suicides are the results of impulsive decision-making. When feelings of hopelessness occur in the context of narrowing of prospects accompanied by loss of options for coping, suicide vulnerability reaches its peak.

When an inmate expresses ideas of helplessness in the context of narrowing of options and coping, the inmate is at imminent risk.

Suicide risk factors when they are present in clusters increase the likelihood of suicide. Not any single factor, except probably a prior near-lethal suicide attempt, increases the risk. Risk factors must occur in the context of a pathogenic mental state in an individual who is prone to impulsive acting out.

Understanding the inmate risk factors and their relationships to suicide by health-care providers and correctional officers is fundamental to preventing suicide and avoiding potential liability lawsuits. Often, the providers are at a loss as to how to identify an inmate at risk and provide appropriate interventional help. A high degree of suspicion coupled with appropriately completing screening procedures and risk assessments, and compliance with jail/prison policies and procedures, are the first steps.

\section{Multidimensional Prevention Program}

Suicide prevention is a collective responsibility [10]. The medical and mental health staff, administration, and correctional officers have specific roles in keeping jails and prisons safe. Mental health professionals perform the risk assessment, mental health evaluation, medication management, and mental health review of inmates in administrative segregation and crisis management. The correctional officers conduct the initial screening and monitor the inmate on watch. They observe any changes in behaviors and obvious mental symptoms, report them to mental health providers, and conduct suicide watch and monitoring. The medical staff performs the physical assessment, chronic care, and emergency management, including care after hanging, for inmates. The administration provides the facility's structure and organization and is responsible for creating an attitude among the staff that suicides can and should be prevented. Compartmentalization of responsibilities is the norm, yet the staff must all work together.

A multidimensional approach for the implementation of the programs offers the best way to prevent suicide. Despite all these measures, some inmates pro- 
vide no clues of their suicidal intent. Then, some end their lives accidentally during apparent attempts.

The clinical, programmatic, and research-based strategies depend on legally defensible, clinically sound policies, procedures, and practices. Specifically, the policies must cover suicide prevention and intervention, delivery of mental health service, and medication administration, including involuntary medication and treatment of the seriously mental ill. The most critical procedures include 1) screening of all incoming inmates [22], 2) suicide risk assessment of inmates at risk, 3) suicide watch and monitoring, 4) classification and housing of inmates, 5) suicide risk reassessment, 6) psychiatric and therapeutic encounters, and 7) management of inmates in administrative segregation and special housing. The practice components of the multidimensional suicide-prevention program focus on how the policies and procedures are implemented. While a jail or prison may have a well-reasoned, comprehensive policy and procedures consistent with the NCCHC standards [23], implementation is the key to prevent suicide and avoid legal claims.

\subsection{Screening and Risk Assessment}

There is no standard suicide screening questionnaire applicable to the correctional system. Based on the known factors that increase the likelihood of suicide, a useful screening questionnaire is proposed below. The questionnaire should be administered by a mental health professional or a trained correctional officer at booking:

1) Is the detainee thinking about harming himself?

2) Does the arresting officer believe that the detainee may take his life?

3) Does the detainee have a psychiatric/mental health history, including psychotropic medication use?

4) Has the detainee made a previous near-lethal suicide attempt such as attempted hanging or overdose during the preceding year?

5) Does the detainee have a history of drug or alcohol abuse?

6) Is the detainee intoxicated with alcohol or drugs at the time of booking?

7) Does the detainee lack close family or friends in the community?

8) Has the detainee experienced a significant loss within the last six months?

9) Does the detainee hold a position of respect in the community?

10) Is the detainee accused of or charged with a shocking crime?

11) Is the detainee suffering from acute pain or a chronic intractable medical condition?

12) Is the detainee feeling helpless, hopeless, anxious, agitated, or trapped?

Each question should have a provision to mark yes or no and explain. Questions concerning current positive suicidal ideation and past near-lethal attempts should be given more weight in assessing the inmate's potential risk. The arresting officer's feelings, though subjective, must be given careful consideration. 


\subsection{Risk Assessment Interview}

The risk assessment clinical interview and a mental status examination is conducted after a referral from the intake worker or a correctional officer who suspects that an inmate is at risk. The critical risk factors identified in the suicide screening questionnaire should be further explored during the clinical interview.

A qualified mental health professional such as a licensed professional counselor, social worker, psychologist, or psychiatrist must conduct the interview. At the outset of the clinical interview, the evaluator must gather information from the correctional officer or any person who placed the inmate on suicide watch. It is unusual that a mental health professional contact a family member, but any information received by the jailers from a family member must be shared with the evaluator. Obligatory sharing of information by the correctional officer with the mental health professional fulfills the staff's collective responsibility, specifically in identifying an inmate at risk, because the officers are tasked to monitor inmates under suicide watch.

The interview is preferably conducted in a semi-structured format [24] to comport with psychiatric disorders and mental state correlated with suicide risk. It usually takes about 30 to 40 minutes. During the interview, it is appropriate to ask direct questions without being judgmental about suicidal ideation, intent, and plan. Questions should focus on the following:

1) Is the inmate entertaining suicidal ideation?

2) Does the inmate have a plan and intent to harm himself?

3) Has the inmate made any previous suicide attempt, and if so, what was the nature of the attempt?

4) Is the inmate apprehensive about problems other than the current situation?

5) Does the inmate feel helpless, hopeless, or that he has nothing to look forward to?

6) Does the inmate show signs of depression such as crying, social withdrawal, emotional flatness, emotional overactivity, or depressed mood?

7) Is the inmate overly anxious, afraid, or angry?

8) Does the inmate feel unusually embarrassed or ashamed of the situation?

9) Does the inmate act strangely?

10) Does the inmate appear under the influence of drugs or alcohol?

11) Does the inmate show signs of withdrawal from drugs?

12) Does the inmate suffer from a depressive disorder, anxiety disorder, or psychotic disorder?

13) Does the inmate have symptoms of post-traumatic stress disorder?

14) Does the inmate have adequate coping and cognitive resources?

15) Does the inmate have an adequate support system?

\subsection{Risk Analysis}

The final step in suicide risk assessment is the risk analysis, the process with 
which the evaluator or the treatment team synthesizes all the relevant static and dynamic risk factors in the context of protective factors, including the relevant data from the screening questionnaire and clinical interview. The evaluator must check the consistency of the information across the data gathering process. Any inconsistency between the denial and behavior pattern may raise questions on the veracity of suicidal ideation and behaviors.

The risk analysis allows the determination of the level of supervision, clinical and custodial monitoring needs, and treatment needs of those who are identified as at risk. The level of the watch can be on a continuum of the constant watch, an intermittent watch every 15 minutes to suicide observation every 30 minutes to transfer to release to the general population. Based on the analysis, the mental health professional decides to keep an inmate on suicide watch until his risk mitigates or releases him from the watch and transfers him out of the observation cell to the general population. Proper suicide watch procedures and timely and accurate documentation of the watch and associated behavioral observation must be done.

A reassessment at critical points in an inmate's life during incarceration, such as a court proceeding, sentencing, and any significant psychosocial stressor, including impending divorce and loss of a loved one, would be important to assess any dynamic factors affecting potential suicidality and tracking all those who are classified as being at risk of suicide by admitting them to a chronic care clinic.

Timely medical intervention is needed for those who are found during suicide attempts.

\section{Communication}

Communication between the inmates and officers can be improved if the officers would take time to relate and listen to them empathetically. They should communicate their observations of inmate behavior and emotional changes to mental health. It is important that medical services requests are picked up daily and triage them to give the inmate the assurance that their concerns are taken seriously. Use of functioning intercom in the cell for the inmates to communicate with the officers may be helpful.

\section{Use of Security Camera}

It has been suggested that use of 24-hour security camera may decrease the number of suicides. However, due to privacy concerns it is not advisable.

\section{Mental Health Services Delivery System}

\subsection{Access to Mental Health (MH) Care}

The mental health $(\mathrm{MH})$ services delivery system must ensure inmates' access to mental health services. To that extent, timely response to any MSR would avoid any delay in mental health and psychiatric services. 


\subsection{Treatment for the Seriously Mentally Ill (SMI) Inmates}

Besides the security and custody scores in prisons, the classification of inmates considers the $\mathrm{MH}$ score, which ranges from 1 to 5 . An inmate with no mental health problems may be assigned an $\mathrm{MH}$ score of 1 . A score of 2 represents mild mental health problems, requiring intervention using medications during a crisis. An MH score of 3 represents moderate mental health problems with a diagnosed mental disorder, and they more often are placed on psychotropic medications. An $\mathrm{MH}$ score of 4 represents severe mental health problems requiring acute management with medications and mental health observation, and an $\mathrm{MH}$ score of 5 represents extreme mental health problems that often require inpatient psychiatric admission. An inmate who scores 3, 4, or 5 is classified as seriously mentally ill (SMI), often diagnosed with schizophrenia, bipolar disorder, major depressive disorder, and psychotic disorders. SMl inmates are enrolled in a chronic care clinic where they can be followed with psychotropic medications, case management, and supportive therapy. When necessary, acutely mentally ill and imminently suicidal inmates may be transferred to a state hospital or a crisis stabilization unit promptly, if available within the facility.

\subsection{Solitary Confinement}

Placing a mentally ill inmate in solitary confinement or administrative segregation is counterproductive. The American Psychiatric Association position statement adopted by the board of trustees in 2012 and retained in 2017 states, "Prolonged segregation of adult inmates with serious mental illness, with rare exception, should be avoided due to potential for harm to such inmates. Out-of-cell therapeutic activities and structured time should be provided" [25]. If placed in solitary confinement, some mentally ill inmates decompensate with increased anxiety, depression, and hopelessness, contributing to suicide propensity. Inmates in administrative segregation must be monitored for suitability of the continued placement weekly with a mental health evaluation and suicide risk assessment.

\subsection{Medication Management}

Proper medication management of mentally ill suicidal inmates is a valuable tool for suicide prevention. Policies and procedures to address the need to prescribe, administer, and monitor psychotropic medications are significant components of a comprehensive suicide-prevention program. Before an inmate is placed on medication, an assessment of the appropriateness for the use of medications must be completed. The determination includes psychiatric diagnosis, laboratory tests, assessment of clinical risks and benefit, potential drug-to-drug interactions, evaluation of previous medication trials, and assessment of comorbid physical conditions. In addition, previous psychiatric records of the inmate from community facilities may be obtained and consulted. Prescriptions and frequency of monitoring must be consistent with clinical standards. Consent from 
the inmate for treatment should be obtained.

Medications must be administered on a "watch take" basis to make sure the inmate is compliant with medications and to avoid hoarding. Medication noncompliance management procedure to capture noncompliant inmates must be ensured. Finally, it is better to avoid medications with lethal potential, including tricyclics, and abusive potential such as benzodiazepines.

\subsection{Involuntary Medication Administration}

The US Supreme Court has long recognized an inmate's right to refuse treatment based on the Fourteenth Amendment. Such a right must be balanced against the state's right to treat the mentally ill inmate and run a safe institution. Consistent with the Supreme Court decision on Washington v. Harper [26], adequate due process procedures are put in place by many prisons without the requirement of a court review of a medical decision to administer involuntary psychotropic medications to a gravely disabled, mentally ill inmate who poses a risk to himself or others but refuses medication treatment.

The criteria usually include that the inmate has a serious psychiatric disorder consistent with DSM-5 criteria and is gravely disabled, rendering him unable to make treatment decisions and provide for his basic physical needs. Impairment in cognitive functioning, reality testing, and volitional control may cause the inmate to consider serious harm to himself or others. In this context, psychotropic medications are likely to reduce suffering and risk and improve clinical outcomes. The inmate's refusal to accept pharmacological treatment is a deciding factor for involuntary medications.

\subsection{Medication-Assisted Treatment of Alcohol, Opiate, and Benzodiazepine Withdrawal}

Over $20 \%$ of inmate suicides in jails occur during withdrawal from alcohol and drugs [27]. Specifically, withdrawal from alcohol, opiates/heroin, and benzodiazepine is correlated with suicide and serious suicide attempts, more so in jails than prisons. The suicides usually occur during the first 7 to 10 days of detention. Therefore, all jails should have protocols to assess, detox, and treat alcohol and substance withdrawal, preferably using medication-assisted protocols.

\section{Staff Training to Spot and Intervene in Inmates Who Are at Risk}

Upon initial employment, and on an ongoing basis, all correctional and mental health staff should be trained on all aspects of suicide prevention, including mental disorders and suicide-prevention policies, procedures, and practices. Mental health professionals rely on their professional skills and training by virtue of their education and licensing requirements. However, they may still require facility-specific training. In addition, mental health professionals must be trained to improve their mental health diagnostic skills, suicide risk assessment 
techniques and their communication with correctional officers. And Registered nurses and licensed practical nurses must be trained on facility-specific medication administration policies and practices.

The standard practice of initial training consists of 4 hours of didactic lectures using a syllabus and curriculum covering all areas identified above. Annually, each employee will receive a minimum of two hours of in-service training. Each facility may assign a qualified instructor to provide the training. Initial training is usually provided in a state-run academy.

\section{Role of Administrators}

In addition to maintaining the facility's overall safety and security of the inmates, the Sheriff and chief administrator are responsible for developing and implementing 1) policies and procedures for inmate health care, 2) necessary inmate medical and mental health treatment, 3) policies and procedures of suicide prevention and intervention, 4) policies and procedures relating to the control, delivery, and administration of prescription and nonprescription medications, 5) policies and procedures relating to the provision of inmate programs and services, and 6) employee training of policies, procedures, and practices.

Finally, the administration must create an attitude among the staff that suicides and serious suicide attempts are preventable.

\section{Conclusion}

The multidimensional and multifaceted program involving all stakeholders, including administrators, mental health staff, and medical and correctional staff, has a greater chance to save lives and to mount an effective strategy for any potential liability claim.

\section{Conflicts of Interest}

The author declares no conflicts of interest regarding the publication of this paper.

\section{References}

[1] Mumola, C.J. (2005) BJS Analyst: Suicide and Homicide in State Prisons and Local Jails. Special Reprot, Bureau of Justice Statistics, Washington DC.

[2] U.S. Supreme Court (1978) Monell v. Department of Social Services of the City of New York. No. 75-1914.

[3] US District Court for the Southern District of Texas (1980) Ruiz v. Estelle, 503 F. Supp 1265, [S.D Tex].

[4] United States Court of Appeals (1977) Bowring v. Godwin, 551 F.2d.44, 47 [4th Circuit].

[5] US Supreme Court (1994) Farmer v. Brennan, 511 U.S.825, 836.

[6] United States Court of Appeals (2017) United States Court of Appeals, 3rd Circuit: Palakovic v. Wetzel, 854 F.3d 209.

[7] Estate of Kempf v. Washington City, M. D, Pa, No. CV.15-1125, 2018, WL4354547.

[8] Lewis v. Northumberland County Jail, M. D, Pa, No CV 4:14-CV-02126. 
[9] Curtin, S.C., Warner, M. and Hedegaard, H. (2016) Increase in suicide in the United States, 1999-2014. https://www.cdc.gov/nchs/products/databriefs/db241.htm

[10] Daniel, A.E. (2007) Preventing Suicide in Prison-A Collaborative Responsibility of Administrative, Custody and Clinical Staff. Journal of American Academy of Psychiatry and the Law, 34, 165-175.

[11] Ann Carson, E. and Cowhig, M.P. (2020) Mortality in Local Jails, 2000-2016: Statistical Tables. https://www.bjs.gov/content/pub/pdf/mlj0016st.pdf

[12] Mortality in state and federal prisons, 2001-2016. https://www.bjs.gov.content/pub/pdf.msfp0116st.pdf

[13] Konrad, N., Daigle, M.S., Daniel, A.E., Dear, G., Frottier, P., Hayes, L.M., Kerkhof, A., Liebling, A. and Sarchiapone, M. (2007) Preventing suicide in prisons. Part I recommendations from the International Association for Suicide Prevention Task Force on Suicide in Prisons. Crisis, 28, 113-121. https://doi.org/10.1027/0227-5910.28.3.113

[14] Daniel, A.E. and Fleming, J. (2006) Suicide in a State Correctional System 1992-2002: A Review. Journal of Correctional Health Care, 12, 24-35. https://doi.org/10.1177/1078345806287541

[15] Daniel, A.E. (2004) Commentary: Decision Making by Front Line Service Providers-Attitudinal or Contextual. Journal of the American Academy of Psychiatry and the Law, 32, 386-389.

[16] United States Court of Appeals, $11^{\text {th }}$ Circuit: Steele v. Shah, 87 F.3d 1266.

[17] Daniel, A.E. and Fleming, J. (2005) Serious Suicide Attempts in Correctional System and Preventive Strategies. Journal of Psychiatry and Law, 33, 227-247. https://doi.org/10.1177\%2F009318530503300204

[18] Joiner Jr., T.E., Van Orden, K.A., Witte, T.K. and Rudd, M.D. (2009) The Interpersonal Theory of Suicide: Guidance for Working with Suicidal Clients. American Psychological Association, Washington DC. https://content.apa.org/doi/10.1037/11869-000

[19] Abramson, L.Y., Metalsky, G.I. and Alloy, L.B., (1989) Hopelessness Depression: A Theory-Based Subtype of Depression. Psychological Review, 96, 358-372. https://doi.apa.org/doi/10.1037/0033-295X.96.2.358

[20] Bonner, R.L. and Rich, A.R. (1990) Psychosocial Vulnerability, Life Stress, and Suicide Ideation in a Jail Population: A Cross-Validation Study. Suicide Life Threatening Behavior, 20, 213-224.

[21] Gvion, Y. and Apter, A. (2011) Aggression, Impulsivity, and Suicide Behavior: A Review of the Literature. Archives of Suicide Research, 15, 93-112. https://doi.org/10.1080/13811118.2011.565265

[22] National Commission on Correctional Health Care (2020) Mental Health Screening and Evaluation. Standard JE-05, Chicago.

[23] NCCHC Standards for Mental Health Services in Correctional Facilities, 2018.

[24] Carlson, D.K. (2002) The Jail Suicide Assessment Tool (JSAT). https://www.usmarshals.gov/prisoner/assessment_tool.pdf

[25] Psychiatry.org (2017) Position Statement on Segregation of Prisoners with Mental Illness. American Psychiatric Association, Washington DC

[26] U.S. Supreme Court (1990) Washington v. Harper, 494 U.S. 210.

[27] Hayes, L. (2010) National Study of Jail Suicide: 20 Years Later. U.S. Department of Justice, National Institute of Justice, Washington DC. 